\title{
Reconfigurable 3/6 dB Novel Branch Line Coupler
}

\author{
Tamer Gaber Abouelnaga1, Ashraf Shawky Mohra² \\ ${ }^{1}$ Microstrip Circuits Department, Electronics Research Institute, Giza, Egypt \\ ${ }^{2}$ Faculty of Engineering, Benha University, Qalyubia, Egypt \\ Email: tamer@eri.sci.eg, amohra@bhit.bu.edu.eg
}

How to cite this paper: Abouelnaga, T.G. and Mohra, A.S. (2017) Reconfigurable 3/6 dB Novel Branch Line Coupler. Open Journal of Antennas and Propagation, 5, 7-22. https://doi.org/10.4236//ojapr.2017.51002

Received: December 2, 2016

Accepted: February 25, 2017

Published: February 28, 2017

Copyright $\odot 2017$ by authors and Scientific Research Publishing Inc. This work is licensed under the Creative Commons Attribution International License (CC BY 4.0).

http://creativecommons.org/licenses/by/4.0/

\begin{abstract}
In this paper, a new idea of reconfigurable $3 / 6 \mathrm{~dB}$ branch line coupler is proposed. The proposed coupler is tuned through a simple open and short circuit at the coupler's branches' edges. At the short edges case, a $3 \mathrm{~dB}$ branch line coupler is obtained. In this case, the coupler's branches are considered as microstrip transmission lines with $0.3 \mathrm{~mm}$ slot width which is etched in each coupler's branch. At the open edges case, the coupler's branches are considered as asymmetric coupled microstrip lines. In this case, a $6 \mathrm{~dB}$ branch line coupler is obtained. Both CST and IE3D simulators are used to optimize the reconfigurable $3 / 6 \mathrm{~dB}$ branch line coupler dimensions. As a prototypes, two BLCs are designed, analyzed and tested at the "on" and "off" states at $2.5 \mathrm{GHz}$. The measured $S$-parameters confirm the proposed concept of the reconfigurable $3 / 6 \mathrm{~dB}$ branch line coupler.
\end{abstract}

\section{Keywords}

Branch Line Coupler, Microstrip Lines, Asymmetric Coupled Microstrip Lines, 3/6 dB Coupler

\section{Introduction}

Branch line couplers, parallel coupled-line couplers, and rat-race hybrids are very important passive components in many wireless communication and microwave systems. There are lots of applications of $90^{\circ}$ hybrid and $180^{\circ}$ hybrid branch-line tight couplers such as $-3 \mathrm{~dB}$ or $-6 \mathrm{~dB}$ coupler in modern microwave and millimeter wave communication systems. It is used widely [1] [2] in adaptive antenna arrays, balanced amplifiers, phase shifters, data modulators, balanced mixers, etc. To develop the 3-dB parallel coupled-line coupler, long coupled lines and tight coupling are often required. In particular, to result in tight coupl- 
ing, the Lange coupler [3] [4] [5], and tandem type [6] [7] [8] [9] have been utilized. However, complicated multilayered circuitry is necessary due to these coupled structures' narrow line widths and narrow gaps between coupled lines. Further, to design the coupling between 3.0 and $6.0 \mathrm{~dB}$, a crossover connection between the output arms may be needed for the planar rat-race hybrid [10]. Fortunately, the branch line coupler can easily achieve the tight coupling using planar structures. The conventional branch-line coupler employs four quarter wavelength $(\lambda / 4)$ transmission lines. Generally good performance and $90^{\circ}$ phase shift between the coupled port and the through port are obtained in the narrow within the vicinity of center frequency. The branch line coupler can be realized using planar transmission line, artificial transmission line [11] and nonuniform trans-mission line [12], but both of the artificial and nonuniform transmission lines are difficult in fabrications. A branch line coupler using the lumped-element with asymmetrical E-equivalent sections was described at [13] for bandwidth enhancement, but the lumped element $S$-parameters was varied at higher frequency. A compact $3 \mathrm{~dB}$ branch-line coupler using substrate integrated suspended line (SISL) technology was proposed in [14], but it had a lot of complexity due to multilayer fabrication process. In [15], a miniaturization of the conventional branch line coupler was done by adding open stub to the series and parallel transmission line of the conventional $3 \mathrm{~dB}$ coupler. Although such design gives a better performance, it suffers from the decrease in the operating bandwidth. The same idea was used with replacing the traditional $\lambda / 4$ lines with multi-T-shaped lines [16], but multi-T shaped lines affected the phase difference between the two output ports. Another method without lumped components or DGS structure is applied to realize the miniaturization of branch-line coupler. Firstly, a novel center-symmetrical spiral-interdigital resonator (CSSIR) was presented, then a miniaturized branch-line coupler, which was with the CSSIR unit cells embedded into the branch and parallel lines, was designed [17]. The overall operating bandwidth is small due to spiral interdigital resonators. A branch line coupler with a wide passband, utilizing multi sectional idea is given in [18]. The overall size of such coupler is very large and can be nearly minimized using the defected ground structure under the vertical branches. In this article, a new idea of reconfigurable $3 / 6 \mathrm{~dB}$ branch line coupler is proposed, where it uses only a simple open and short circuit at branch line coupler edges to develop $3 \mathrm{~dB}$ or $6 \mathrm{~dB}$ branch line coupler.

\section{Analytical Analysis and Design of Branch Line Coupler}

In the branch line coupler presented in Figure 1, the characteristic impedances of the through and branch lines are $Z_{1}, Z_{2}$ and their lengths are $\theta_{1}$ and $\theta_{2}$ respectively. This type of construction enables one to deal with four variables, two characteristic impedances and two lengths. The analysis of the branch-line coupler leads to three design equations with which a hybrid with any power division ratio can be designed readily. Suppose that Port 1 and 4 are excited by two signals of amplitude $1 / 2$ and in phase, by symmetry a voltage maximum occurs 


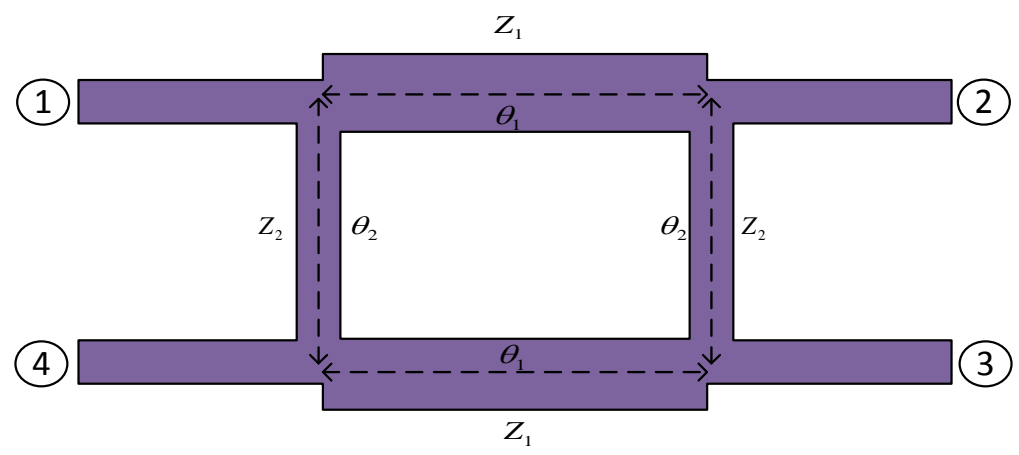

Figure 1. Unequal line-length branch-line coupler.

at every point on the line of symmetry. This is the equivalent of an open circuit. Similarly, if two signals are of amplitude $1 / 2$ and out of phase, a voltage minimum occurs at every point on the line of symmetry. This is the equivalent of a short circuit. By superposition, the sum of the two cases is a single signal of unit amplitude in Port 1. The resultant signals out of the four ports are also the superposition of the results obtained in the even mode and odd mode case. In each case, the problem reduces to that of a two port network.

\subsection{Even and Odd Mode Analysis}

For the even mode Figure 2, a reflection coefficient $\Gamma_{e}$ and a transmission coefficient $T_{e}$ are determined. Similarly, for the odd mode Figure 3, $\Gamma_{o}$ and $T_{o}$ are also determined [1]. By superposition the vector amplitudes of the signals emerging from the four ports are:

$$
P_{1}=0.5\left(\Gamma_{e}+\Gamma_{o}\right) .
$$

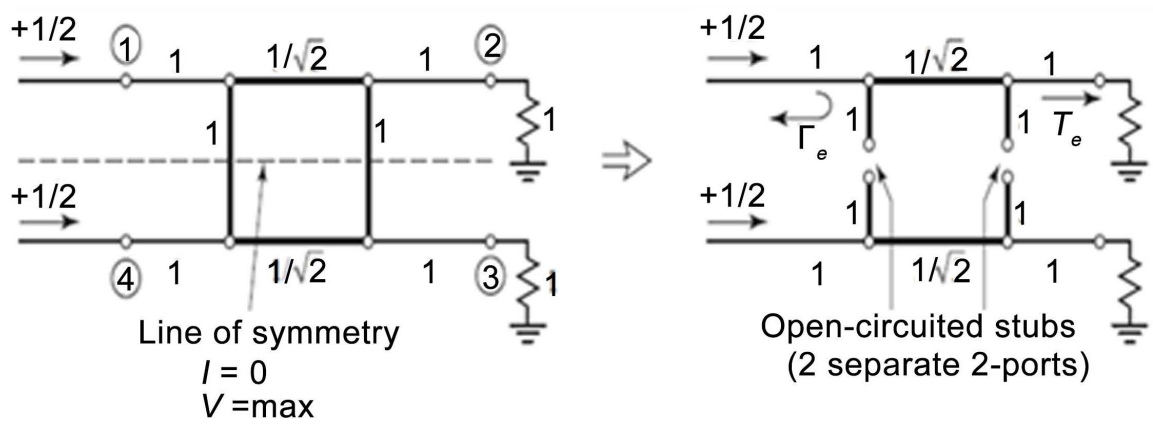

Figure 2. Decomposition of branch line coupler into even-mode excitation.

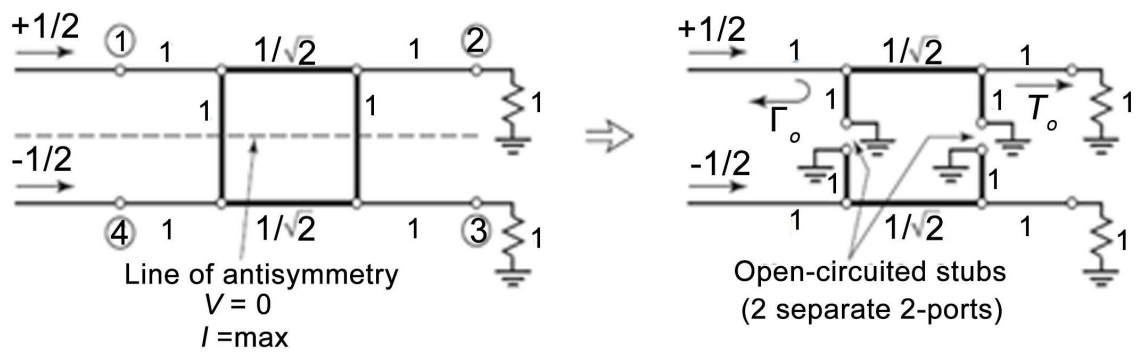

Figure 3. Decomposition of branch line coupler into odd-mode excitation. 


$$
\begin{gathered}
P_{2}=0.5\left(T_{e}+T_{o}\right) . \\
P_{3}=0.5\left(T_{e}-T_{o}\right) . \\
P_{4}=0.5\left(\Gamma_{e}-\Gamma_{o}\right) .
\end{gathered}
$$

For even mode, the $A B C D$ parameters could be written as Equation (2) and $\mathrm{ABCD}$ parameters are given by Equation (3).

$$
\begin{gathered}
{\left[\begin{array}{ll}
A & B \\
C & D
\end{array}\right]_{e}=\left[\begin{array}{cc}
\frac{1}{j \tan \left(\frac{\theta_{2}}{2}\right)} & 0 \\
Z_{2} & 1
\end{array}\right]\left[\begin{array}{cc}
\cos \left(\theta_{1}\right) & j Z_{1} \sin \left(\theta_{1}\right) \\
\frac{j \sin \left(\theta_{1}\right)}{Z_{1}} & \cos \left(\theta_{1}\right)
\end{array}\right]\left[\begin{array}{cc}
1 & 0 \\
A_{e}=D_{e}=\cos \left(\theta_{1}\right)-\frac{Z_{1}}{Z_{2}} \sin \left(\theta_{1}\right) \tan \left(\frac{\theta_{2}}{2}\right) & 1
\end{array}\right] .} \\
B_{e}=j Z_{1} \sin \left(\theta_{1}\right) . \\
C_{e}=\left(j 2 \frac{1}{Z_{2}} \cos \left(\theta_{1}\right) \tan \left(\frac{\theta_{2}}{2}\right)\right)+j \sin \left(\theta_{1}\right) \frac{1}{Z_{1}}\left[1-\left(\frac{Z_{1} \tan \left(\frac{\theta_{2}}{2}\right)}{Z_{2}}\right)^{2}\right] .
\end{gathered}
$$

For odd mode, the $\mathrm{ABCD}$ parameters could be written as Equation (4) and the $\mathrm{ABCD}$ parameters are given by Equation (5).

$$
\begin{aligned}
& {\left[\begin{array}{ll}
A & B \\
C & D
\end{array}\right]_{0}=\left[\begin{array}{cc}
1 & 0 \\
\frac{1}{j \tan \left(\frac{\theta_{2}}{2}\right) Z_{2}} & 1
\end{array}\right]\left[\begin{array}{cc}
\cos \left(\theta_{1}\right) & j Z_{1} \sin \left(\theta_{1}\right) \\
\frac{j \sin \left(\theta_{1}\right)}{Z_{1}} & \cos \left(\theta_{1}\right)
\end{array}\right]\left[\begin{array}{cc}
1 & 0 \\
\frac{1}{j \tan \left(\frac{\theta_{2}}{2}\right) Z_{2}} & 1
\end{array}\right] .} \\
& A_{o}=D_{o}=\cos \left(\theta_{1}\right)+\frac{Z_{1} \sin \left(\theta_{1}\right)}{Z_{2} \tan \left(\frac{\theta_{2}}{2}\right)} . \\
& B_{o}=j Z_{1} \sin \left(\theta_{1}\right) \text {. } \\
& C_{o}=\left(-j 2 \frac{\cos \left(\theta_{1}\right)}{Z_{2} \tan \left(\frac{\theta_{2}}{2}\right)}\right)+j \sin \left(\theta_{1}\right) \frac{1}{Z_{1}}\left[1-\left(\frac{Z_{1}}{Z_{2} \tan \left(\frac{\theta_{2}}{2}\right)}\right)^{2}\right] \text {. }
\end{aligned}
$$

Using $\mathrm{ABCD}$ to $S$-parameters transformation [1], and the fact that $A D-B C=1$ and $A=D$.

$$
\begin{gathered}
S_{11}=\Gamma=\frac{B / Z_{o}-C Z_{o}}{2 A+B / Z_{o}+C Z_{o}} . \\
S_{21}=T=\frac{2}{2 A+B / Z_{o}+C Z_{o}} .
\end{gathered}
$$

Matching condition could be met at $S_{11}=0$ which gives $B_{e}=B_{o}$ and $C_{e}=C_{o}$. Using Equation (3.c), Equation (5.c) and $\tan \left(\frac{\theta}{2}\right)=\frac{\sin (\theta)}{1+\cos (\theta)}=\frac{1-\cos (\theta)}{\sin (\theta)}$. The following equation could be written and simplified. 


$$
\begin{gathered}
\left(j 2 \frac{1}{Z_{2}} \cos \left(\theta_{1}\right) \tan \left(\frac{\theta_{2}}{2}\right)\right)+j \sin \left(\theta_{1}\right) \frac{1}{Z_{1}}\left[1-\left(\frac{Z_{1} \tan \left(\frac{\theta_{2}}{2}\right)}{Z_{2}}\right)^{2}\right] \\
=\left(-j 2 \frac{\cos \left(\theta_{1}\right)}{Z_{2} \tan \left(\frac{\theta_{2}}{2}\right)}\right)+j \sin \left(\theta_{1}\right) \frac{1}{Z_{1}}\left[1-\left(\frac{Z_{1}}{Z_{2} \tan \left(\frac{\theta_{2}}{2}\right)}\right)^{2}\right] \\
-1=\frac{Z_{1} \tan \left(\theta_{1}\right)}{Z_{2} \tan \left(\theta_{2}\right)} .
\end{gathered}
$$

Second matching condition states that $B_{e}=C_{e} Z_{o}^{2}$, using Equation (3.b) and (c), the following equations could be written and simplified as:

$$
\begin{gathered}
j Z_{1} \sin \left(\theta_{1}\right)=\left(j 2 \frac{Z_{o}^{2}}{Z_{2}} \cos \left(\theta_{1}\right) \tan \left(\frac{\theta_{2}}{2}\right)\right)+j \sin \left(\theta_{1}\right) \frac{Z_{o}{ }^{2}}{Z_{1}}\left[1-\left(\frac{Z_{1} \tan \left(\frac{\theta_{2}}{2}\right)}{Z_{2}}\right)^{2}\right] . \\
\frac{1}{Z_{o}{ }^{2}}=\frac{1}{Z_{1}{ }^{2}}-\frac{1}{Z_{2}{ }^{2}} .
\end{gathered}
$$

Transmission from Port 1 to Port 2 and from Port 1 to Port 3 could be written using vector representation given by Equation (1) as:

$$
\begin{aligned}
& S_{31}=0.5\left(T_{e}-T_{o}\right) . \\
& S_{21}=0.5\left(T_{e}+T_{o}\right) .
\end{aligned}
$$

Using Equation (6.b) and Equation (9), the following equations could be written and simplified to find the ratio of signals travelling through Ports 2 and 3 which could be formed as $S_{21} / S_{31}$.

$$
\frac{S_{21}}{S_{31}}=\frac{A_{o}+B_{e} / Z_{o}+C_{e} Z_{o}+A_{e}}{A_{o}-A_{e}} .
$$

Equation (10) could be evaluated as:

$$
\begin{gathered}
A_{o}-A_{e}=\frac{Z_{1}}{Z_{2}} \sin \left(\theta_{1}\right)\left[\frac{1}{\tan \left(\frac{\theta_{2}}{2}\right)}+\tan \left(\frac{\theta_{2}}{2}\right)\right]=2 \frac{Z_{1}}{Z_{2}} \frac{\sin \left(\theta_{1}\right)}{\sin \left(\theta_{2}\right)} . \\
A_{o}+A_{e}=2 \cos \left(\theta_{1}\right)+\frac{Z_{1}}{Z_{2}} \sin \left(\theta_{1}\right)\left[\frac{1}{\tan \left(\frac{\theta_{2}}{2}\right)}-\tan \left(\frac{\theta_{2}}{2}\right)\right] \\
=2 \cos \left(\theta_{1}\right)+2 \frac{Z_{1}}{Z_{2}}\left(\cos \left(\theta_{2}\right)\right) \frac{\sin \left(\theta_{1}\right)}{\sin \left(\theta_{2}\right)} . \\
B_{e} / Z_{o}+C_{e} Z_{o}=2 B_{e} / Z_{o}=j \frac{2 Z_{1}}{Z_{o}} \sin \left(\theta_{1}\right) . \\
\frac{S_{21}}{S_{31}}=j \frac{Z_{2}}{Z_{o}} \sin \left(\theta_{2}\right) .
\end{gathered}
$$


Defining the power division ratio $k^{2}$ between the output ports as (power output through Port $2 P_{o 2}$ ) $=k^{2}$ (power input to Port $1 P_{i 1}$ ), where $0<k<1$, one can write from the conservation of power assuming no reflection from Port 1 and fully isolation at Port 4 and lossless system.

$$
\begin{aligned}
& P_{i 1}=P_{o 2}+P_{o 3} . \\
& \frac{\left|S_{21}\right|^{2}}{\left|S_{31}\right|^{2}}=\frac{k^{2}}{1-k^{2}} .
\end{aligned}
$$

Using Equation (11) and Equation (13) the following equation could be written as:

$$
\frac{k Z_{o}}{\sqrt{1-k^{2}}}=Z_{2} \sin \left(\theta_{2}\right) .
$$

This relationship governs the power division between the output ports of the coupler. Figure 4 shows the design and analysis steps for a branch line coupler with any lengths, impedances and division ratios.

\subsection{Conventional $3 \mathrm{~dB}$ Branch Line Coupler}

The three design Equations (7) (8) and (14) could be used for the design of $3 \mathrm{~dB}$ branch line coupler. For the $3 \mathrm{~dB}$ branch line coupler, $k=1 / \sqrt{2}, l_{2}=l_{1} \cong \frac{\lambda}{4}$ and other parameters could be found as $Z_{o}=Z_{2}$ and $Z_{1}=Z_{o} / \sqrt{2}$.

\subsection{Conventional $6 \mathrm{~dB}$ Branch Line Coupler}

The conventional $6 \mathrm{~dB}$ branch line coupler could be designed using the three design Equations (7) (8) and (14). For the $6 \mathrm{~dB}, k=1 / 2, l_{2}=l_{1}=\lambda / 4$ and other values could be found as $Z_{o} / \sqrt{3}=Z_{2}$ and $Z_{1}=Z_{0} / 2$. Table 1 shows different parameters values for $3 \mathrm{~dB}, 6 \mathrm{~dB}, 9 \mathrm{~dB}$ and $10 \mathrm{~dB}$ BLCs. Based on previous equations, a Matlab code has been built to calculate the $S$-parameters for different BLCs. Figures 5-8 show the analytical calculated S-parameters for the for $3 \mathrm{~dB}, 6$ $\mathrm{dB}, 9 \mathrm{~dB}$ and $10 \mathrm{~dB}$ BLCs, respectively. One can notice that an all BLCs resonate at $2.5 \mathrm{GHz}$ but with different division ratios according to Table 1 .

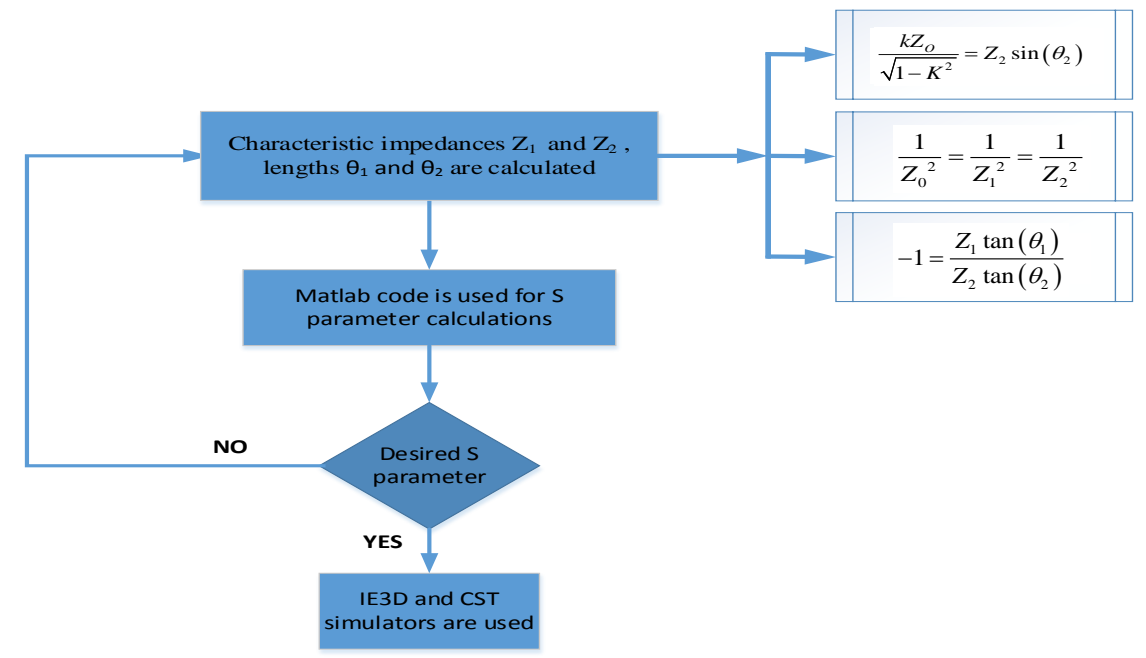

Figure 4. Branch line coupler design and analysis flowchart. 
Table 1. Different parameter values for different division ratio BLC.

\begin{tabular}{cccccc}
\hline BLC & $K$ & $Z_{1}$ & $Z_{2}$ & $l_{1}$ & $l_{2}$ \\
\hline$-3 \mathrm{~dB}$ & $1 / \sqrt{2}$ & $Z_{\mathrm{o}} / \sqrt{2}$ & $Z_{\mathrm{o}}$ & $\lambda / 4$ & $\lambda / 4$ \\
$-6 \mathrm{~dB}$ & $1 / 2$ & $Z_{\mathrm{o}} / 2$ & $Z_{\mathrm{o}} / \sqrt{3}$ & $\lambda / 4$ & $\lambda / 4$ \\
$-9 \mathrm{~dB}$ & $1 / 2 \sqrt{2}$ & $Z_{\mathrm{o}} / 2 \sqrt{2}$ & $Z_{\mathrm{o}} / \sqrt{7}$ & $\lambda / 4$ & $\lambda / 4$ \\
$-10 \mathrm{~dB}$ & $1 / \sqrt{10}$ & $Z_{\mathrm{o}} / \sqrt{10}$ & $Z_{\mathrm{o}} / 3$ & $\lambda / 4$ & $\lambda / 4$ \\
\hline
\end{tabular}

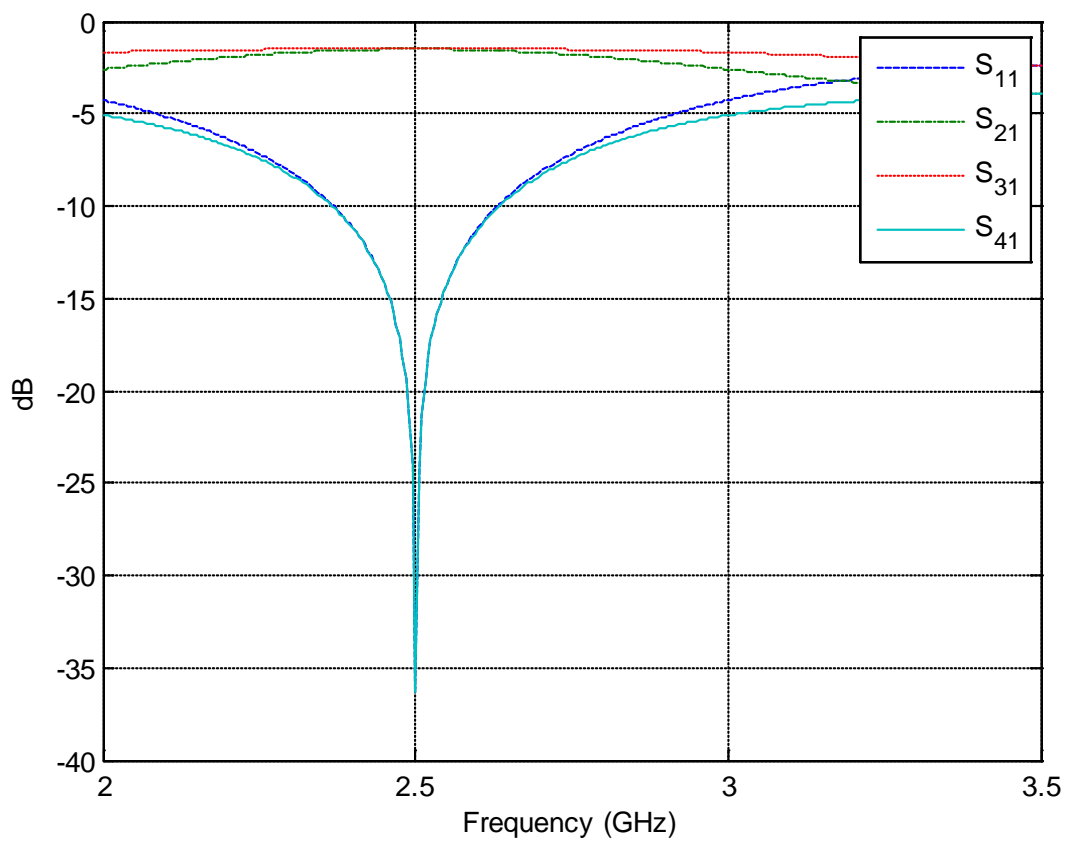

Figure 5. Conventional $3 \mathrm{~dB}$ BLC analytical $S$-parameters.

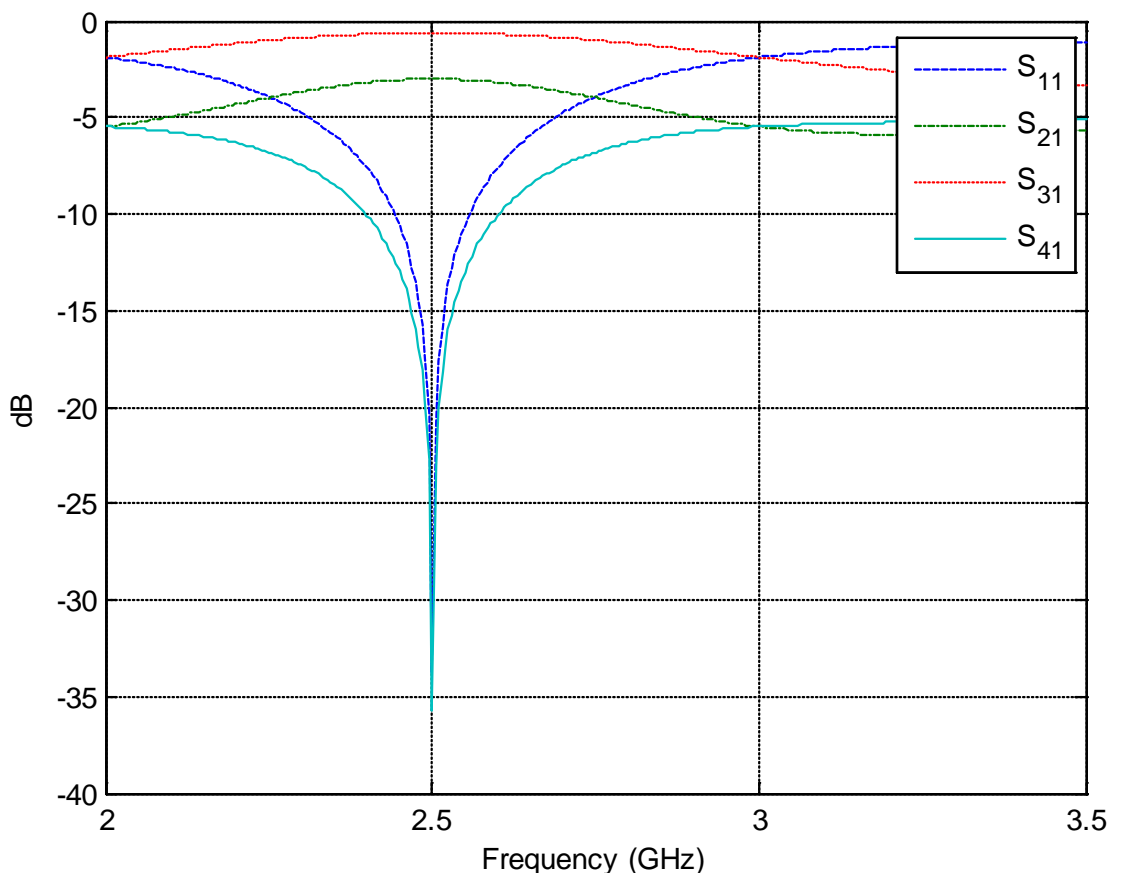

Figure 6. Conventional $6 \mathrm{~dB}$ BLC analytical $S$-parameters. 


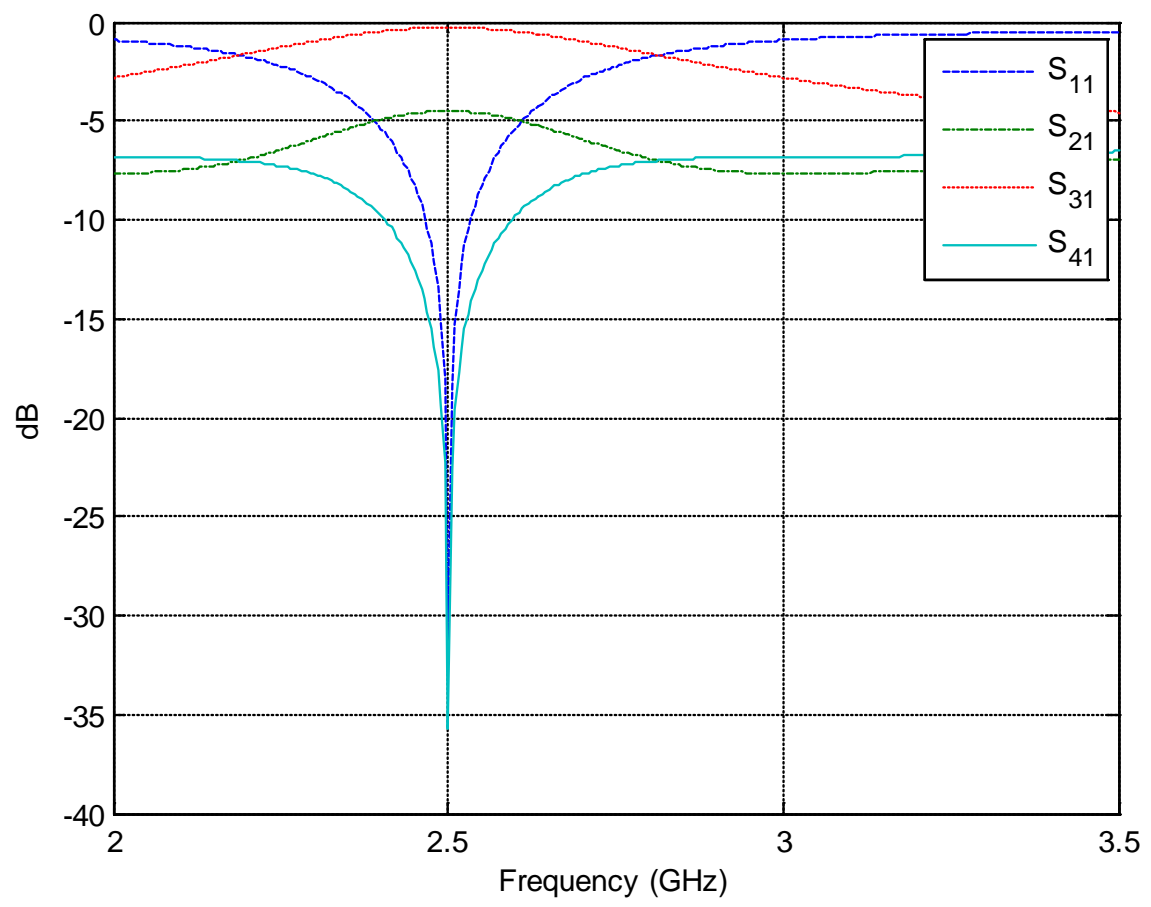

Figure 7. Conventional $9 \mathrm{~dB}$ BLC analytical $S$-parameters.

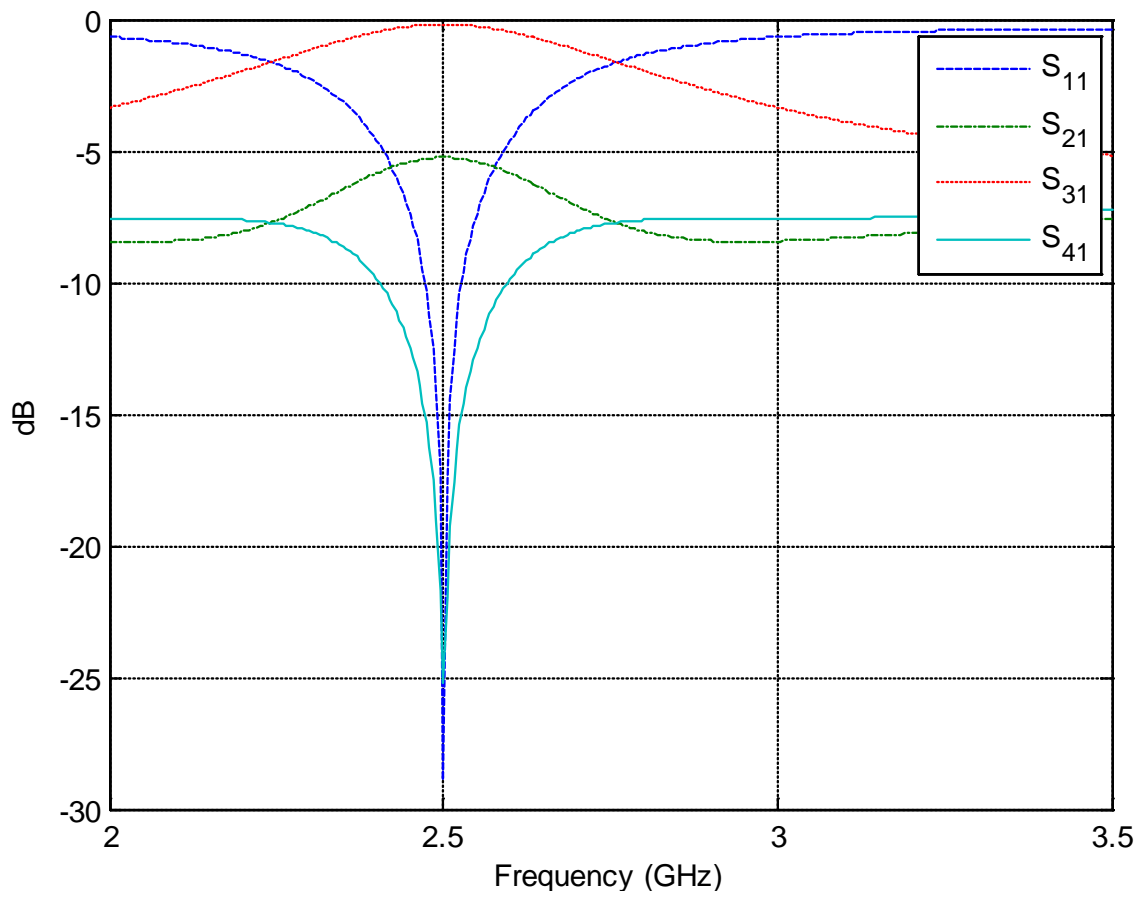

Figure 8. Conventional $10 \mathrm{~dB}$ BLC analytical $S$-parameters.

\subsection{Proposed Reconfigurable $3 / 6$ dB BLC}

The proposed branch-line coupler BLC is composed of four quarter-wavelength transmission-line sections with variable impedances at a designated frequency. Each transmission line consists of two adjacent transmission lines which could be connected or separated at it's edges as shown in Figure 9. Since BLC, 


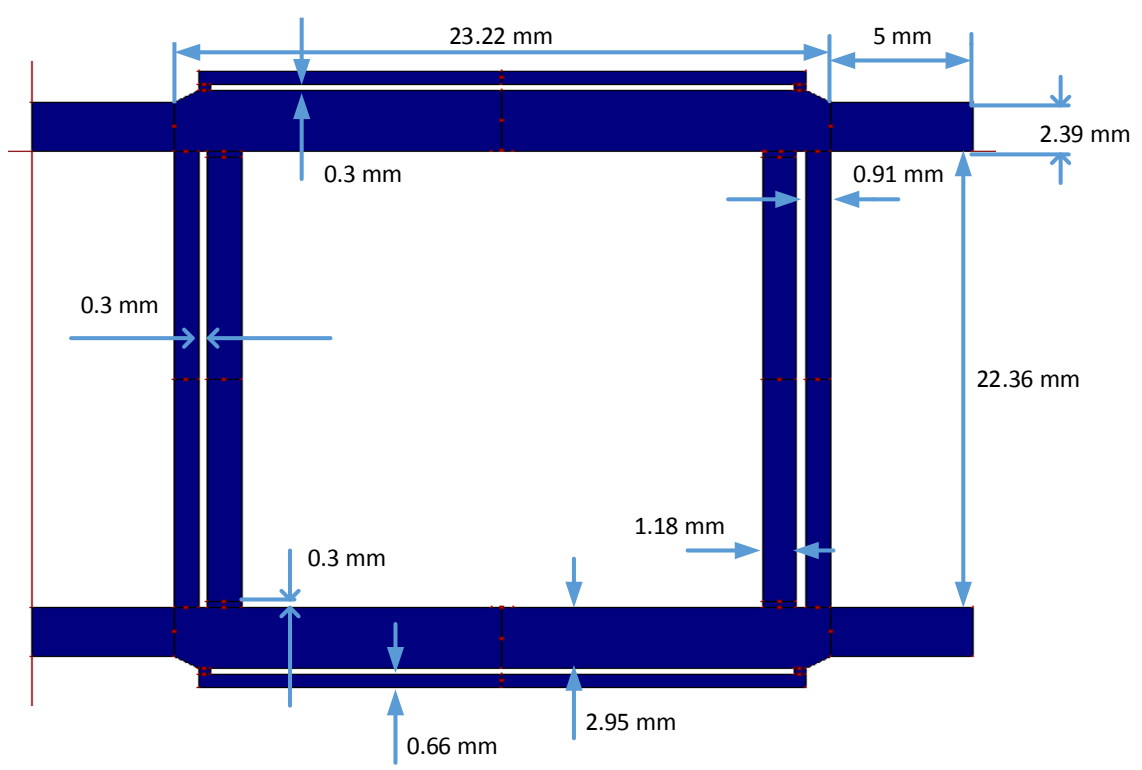

(a)

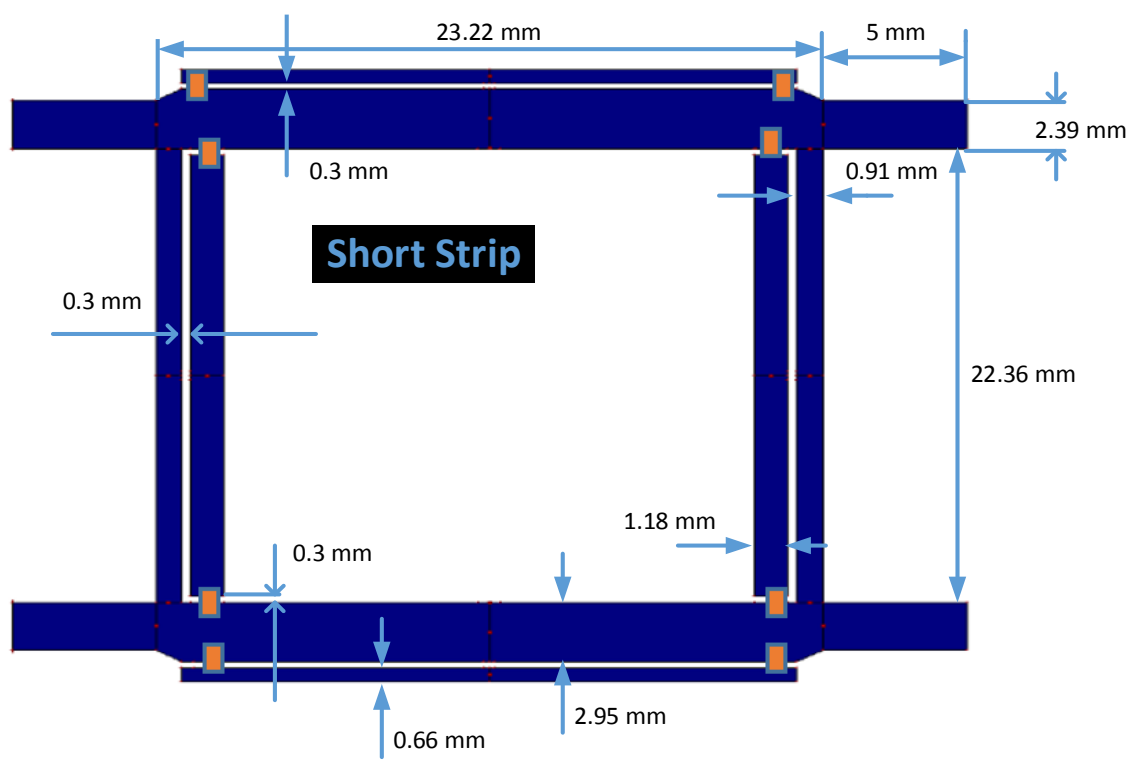

(b)

Figure 9. (a) Proposed reconfigurable $3 \mathrm{~dB}$ branch line coupler; (b) Proposed reconfigurable $3 / 6 \mathrm{~dB}$ branch line coupler.

characteristics including resonant frequency and the power division ratio $k$ are determined mostly by its transmission-line length and impedance, varying its geometry mechanically provides an intuitive method to reconfigure its resonant and division ratio. By using photolithography technique, planar BLC in the form of conductive traces can be fabricated. An open or short process changes dynamically the transmission line section width and enables different division ratio applications. Based on the above analysis and for verification, a reconfigurable $3 / 6 \mathrm{~dB}$ branch-line coupler operating at $2.5 \mathrm{GHz}$ is designed, simulated, and fabricated. For $3 \mathrm{~dB}$ coupler, both $Z_{1}$ and $Z_{2}$ are equal $Z_{0} / \sqrt{2}$ and $Z_{0}$ respectively. Also, both $Z_{1}$ and $Z_{2}$ are equal $Z_{0} / 2$ and $Z_{0} / \sqrt{3}$ respectively 
for the $6 \mathrm{~dB}$ coupler. The coupler is constructed using Teflon substrate with relative dielectric constant $\varepsilon_{r}=2.2$ and thickness $h=0.7874 \mathrm{~mm}$. In the on state the microstrip line sections could be considered as conventional printed microstrip lines [1] and its widths $w$ could be found using Equation (15).

$$
Z_{o}= \begin{cases}\frac{60}{\sqrt{\varepsilon_{r e}} \ln \left(\frac{8 h}{w}+\frac{w}{4 h}\right)} & \text { for } \quad w / h \leq 1 \\ \frac{120 \pi}{\sqrt{\varepsilon_{r e}}[w / h+1.393+0.667 \ln (w / h+1.444)]} & \text { for } w / h>1\end{cases}
$$

where

$$
\varepsilon_{r e}=\frac{\varepsilon_{r}+1}{2}+\frac{\varepsilon_{r}-1}{2} \frac{1}{\sqrt{1+12 h / w}} .
$$

Table 2 shows the calculated dimensions of the $3 \mathrm{~dB}$ BLC. CST [19] and IE3d [20] simulators are used to obtain the $S$-parameters of the $3 \mathrm{~dB}$ BLC after adding a slits of widths of $0.3 \mathrm{~mm}$ to the coupler's branches Figure 9(a). It should be noted that the coupler's branches are still connected at its edges. The optimized dimensions using CST and IE3D are given in Table 2. The difference in dimensions between the theoretical results and numerical results (IE3D and CST software) is attributed to the fact that, in theoretical calculations, each of the boundary conditions and the coupling between adjacent branches are not taking into consideration which make the effective branches width seem be larger in size in the off state, the microstrip transmission section could be considered as asymmetric coupled microstrip lines. In general and ignoring the longitudinal electromagnetic field components the quasi-TEM approach could be used in the analysis of asymmetric two coupled microstrip lines separated by distance $s$ and widths of $w^{\prime}$ and $w^{\prime \prime}$. In this analysis, both c-mode and p-mode were used according to line excitation mode where voltages of signal strips could be different in sign and magnitude [21] [22]. This work stated that both $p$ and $c$ impedances were related to the ratios of $s / h, w^{\prime} / w^{\prime \prime}$ and the relative dielectric constant $\varepsilon_{r}$. So, the BLC performance will be affected much by just make the branches edges open. Based on the obtained results in [21] [22], Ansoft CST and IE3D simulators and keeping the $3 \mathrm{~dB}$ BLC performance in the on state, a $6 \mathrm{~dB}$ BLC performance is obtained at the off state by optimizing of both $s / h$ and $w^{\prime} / w^{\prime \prime}$ for each branch. Figure 9 (b) shows the proposed $3 / 6 \mathrm{~dB}$ branch line coupler using short strip as a switch.

Figure 10(a) and Figure 10(b) show the proposed 3/6 dB BLC $S$-parameters at on conditions using IE3D and CST simulators, respectively, where the 3 $\mathrm{dB}$ point is obtained at $2.5 \mathrm{GHz}$ using IE3D and at $2.6 \mathrm{GHz}$ using CST which may refer to different numerical techniques and different boundary conditions

Table 2. Proposed $3 \mathrm{~dB}$ BLC calculated and optimized dimensions.

\begin{tabular}{lccc}
\hline & Calculated & CST & IE3D \\
\hline$w_{I}(\mathrm{~mm})$ & 4.08 & 3.91 & 3.91 \\
$W_{2}(\mathrm{~mm})$ & 2.519 & 2.39 & 2.39 \\
\hline
\end{tabular}




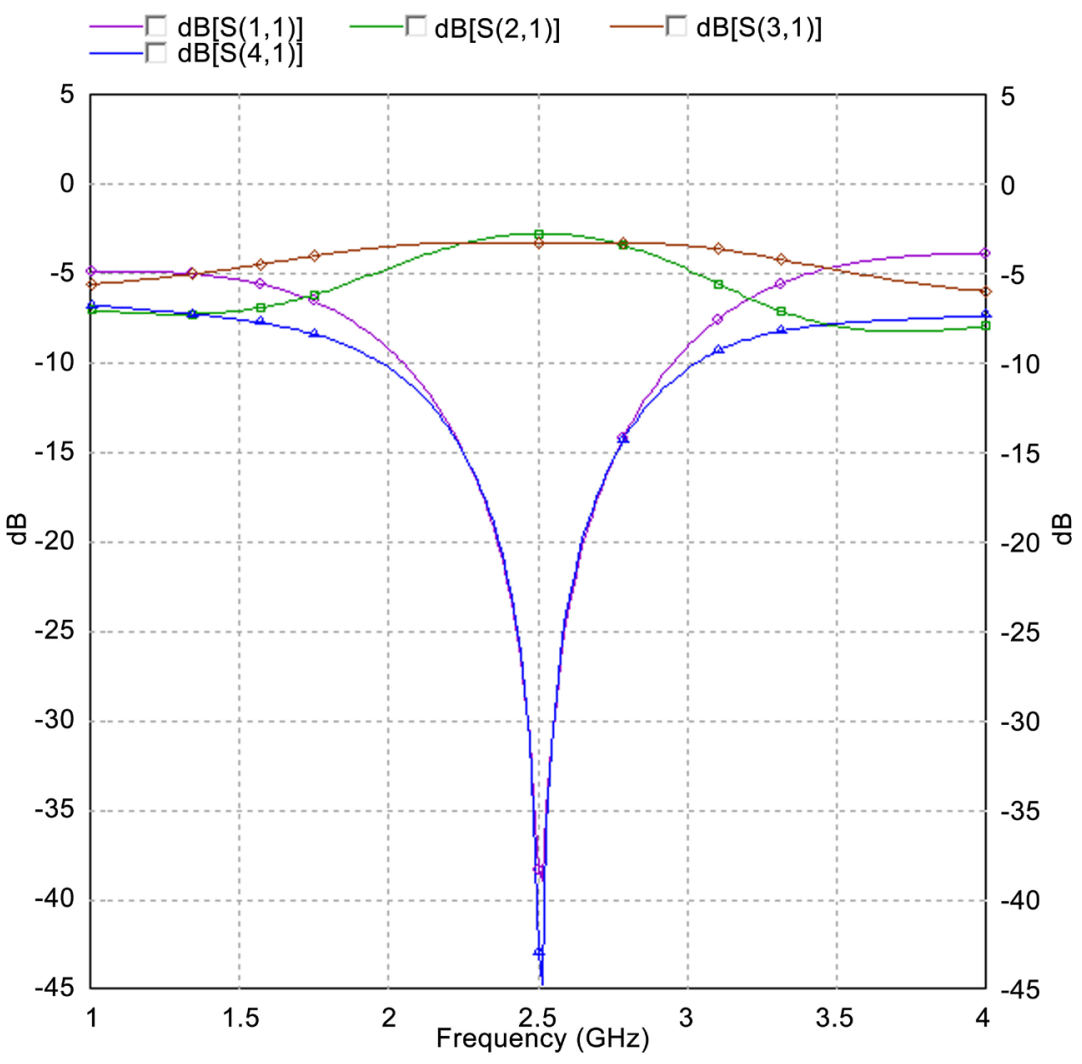

(a)

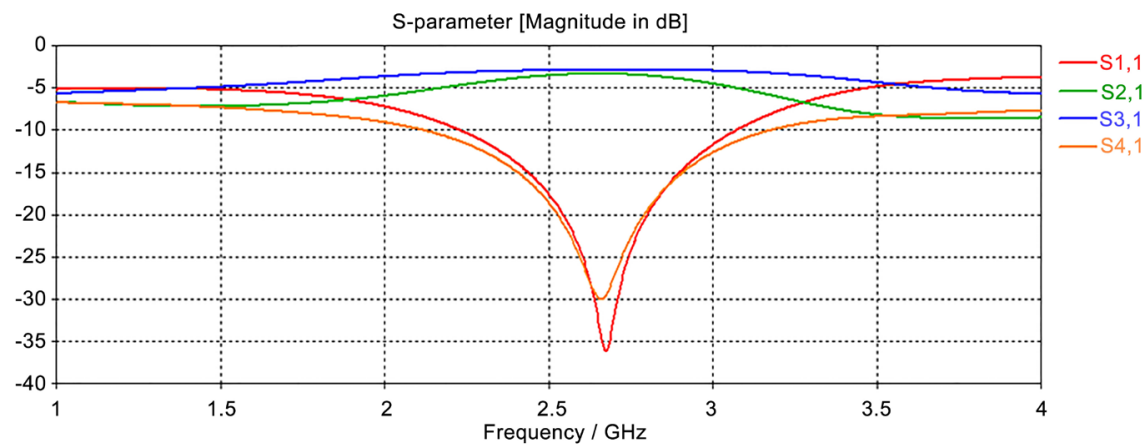

(b)

Figure 10. (a) Proposed 3/6 dB BLC $S$-parameters at on condition (IE3D); (b) Proposed $3 / 6 \mathrm{~dB}$ BLC $S$-parameters at on condition (CST).

that are used by both simulators. Also, Figure 11(a) and Figure 11(b) show the performance at open circuit conditions. One can noticed that the $6 \mathrm{~dB}$ is achieved by just open the BLC branches edges.

The proposed structure is fabricated on Teflon substrate with relative dielectric constant $\varepsilon_{r}=2.2$ and thickness $h=0.7874 \mathrm{~mm}$. As a proof of concept, two BLC prototypes are fabricated, one for the short state and one for the open state in Figure 12. Figure 13(a) and Figure 13(b) show the measured and the simulated $S$-parameters using IE3D and CST respectively at the open state. One can notice that better results agreement is obtained when IE3D simulator is used rather than CST. At $2.5 \mathrm{GHz}$, the difference between $S_{21}$ and $S_{31}$ is almost 


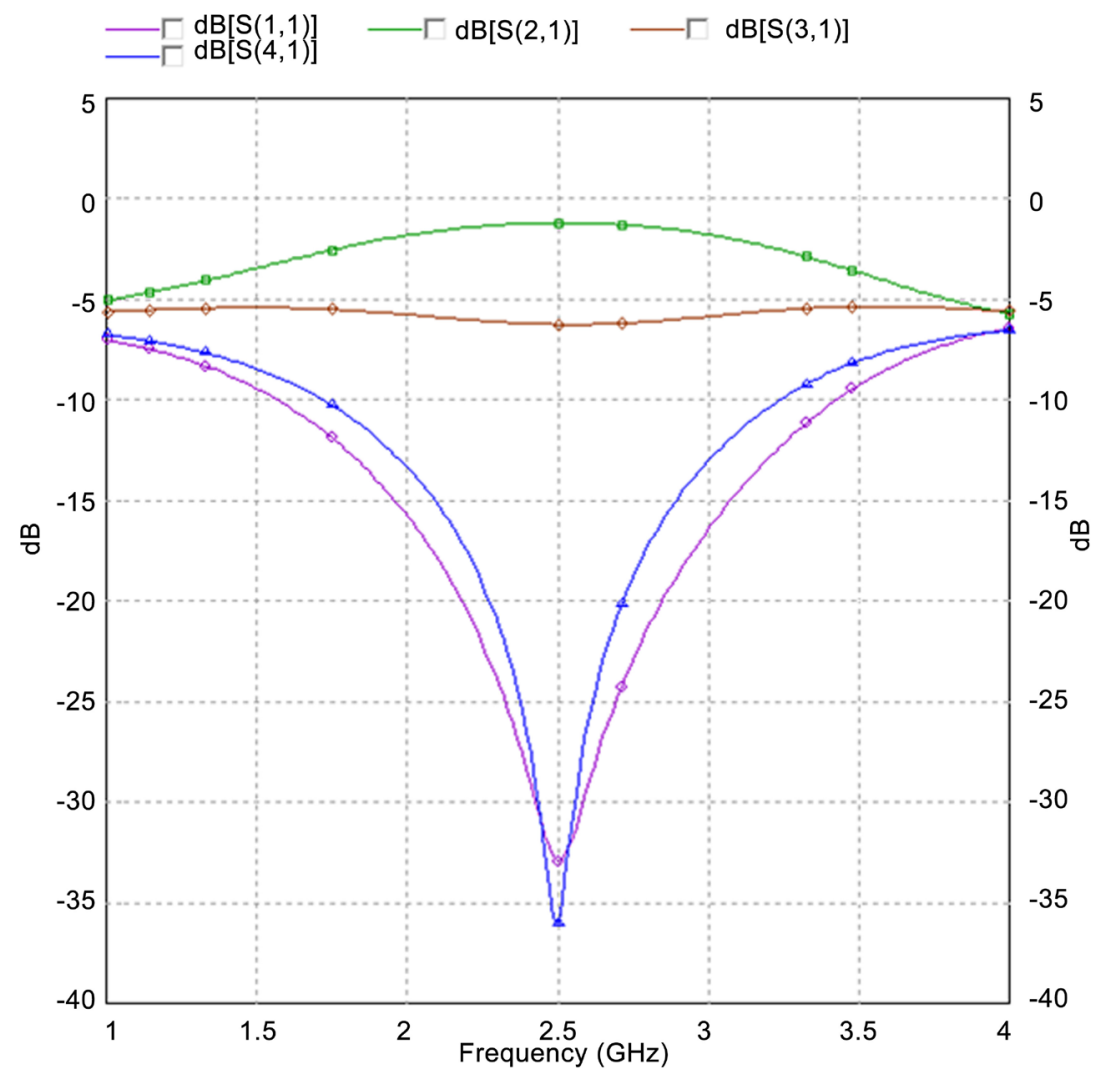

(a)

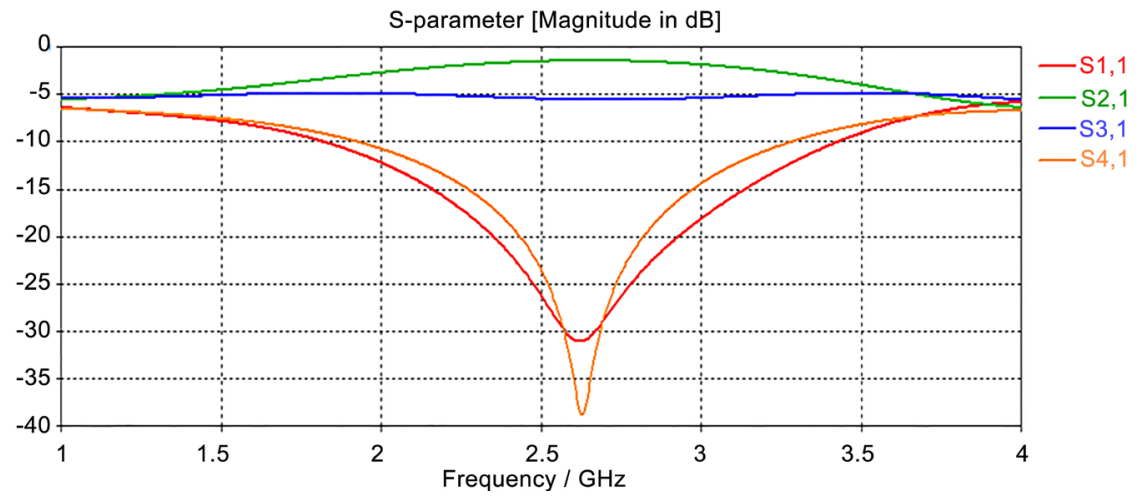

(b)

Figure 11. (a) Proposed 3/6 dB BLC $S$-parameters at off condition (IE3D); (b) Proposed 3/6 dB BLC $S$-parameters at off condition (CST).

the same for both simulated and measured $S$-parameters. Also, Figure 14(a) and Figure 14(b) show both measured and simulated $S$-parameters using IE3D and CST respectively, at the short state. Better results are obtained when IE3D simulator is used rather than CST. At $2.5 \mathrm{GHz}$, the difference between measured $S_{21 m}$ and $S_{31 m}$ and their simulated counterpart is about $1 \mathrm{~dB}$. The obtained results for both simulated and measured results are very close to each other for both open and short states and this little difference may be referred to the connectors and soldering losses that not be taken into account when the proposed structure was simulated. 


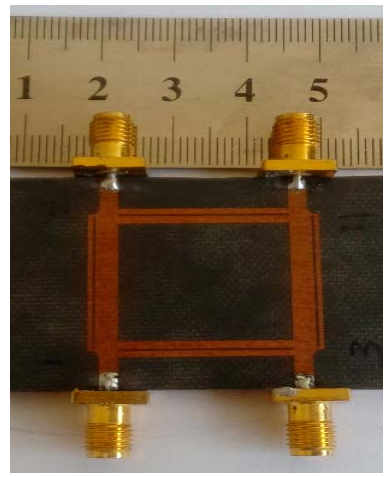

(a)

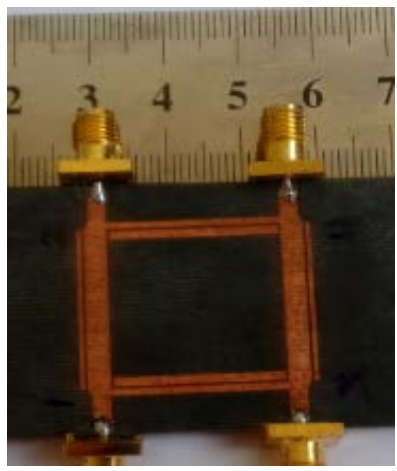

(b)

Figure 12. (a) Proposed 3/6 dB coupler photo with short at branches' edges; (b) Proposed 3/6 dB coupler photo with open at branches' edges.

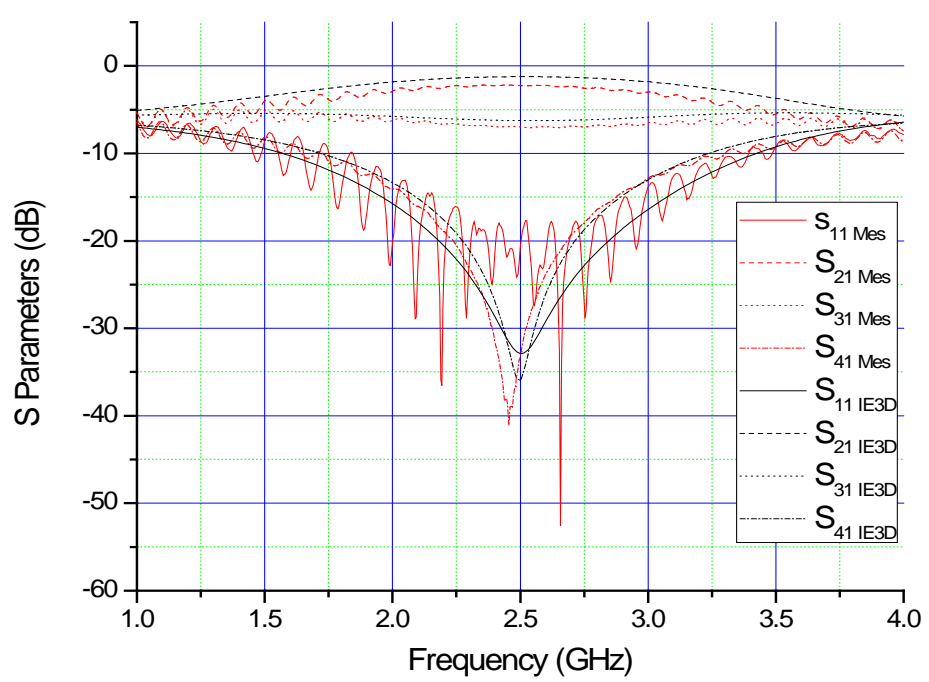

(a)

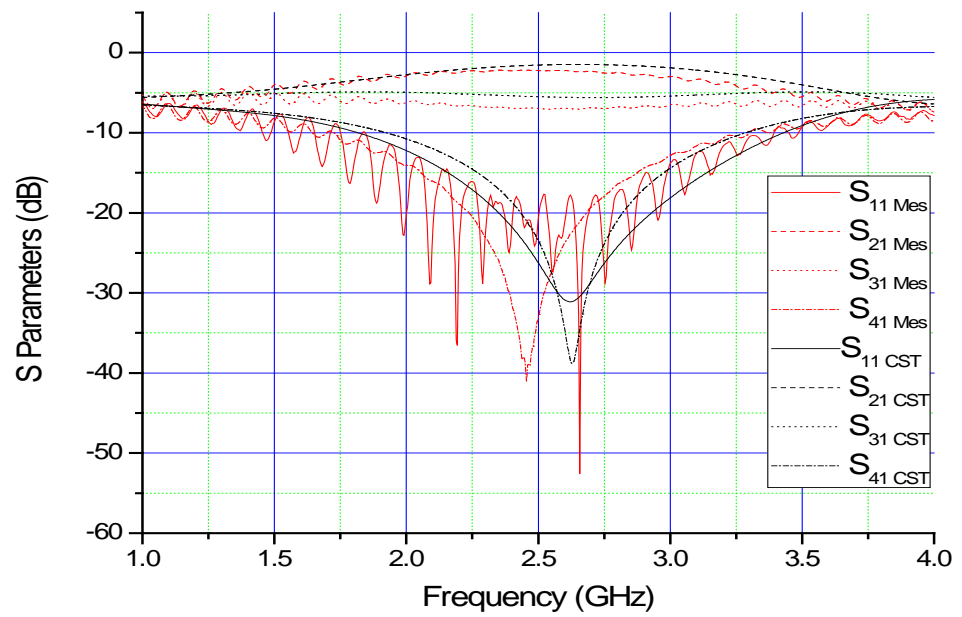

(b)

Figure 13. (a) Proposed 3/6 dB coupler measured and IE3D simulated $S$-parameters at open state; (b) Proposed $3 / 6 \mathrm{~dB}$ coupler measured and CST simulated $S$ parameters at open state. 


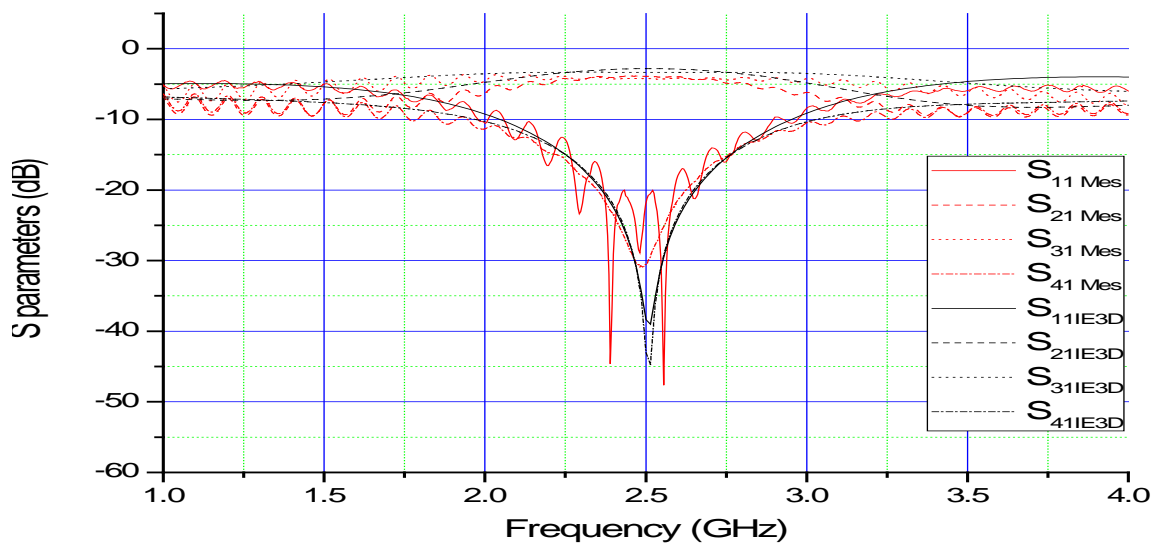

(a)

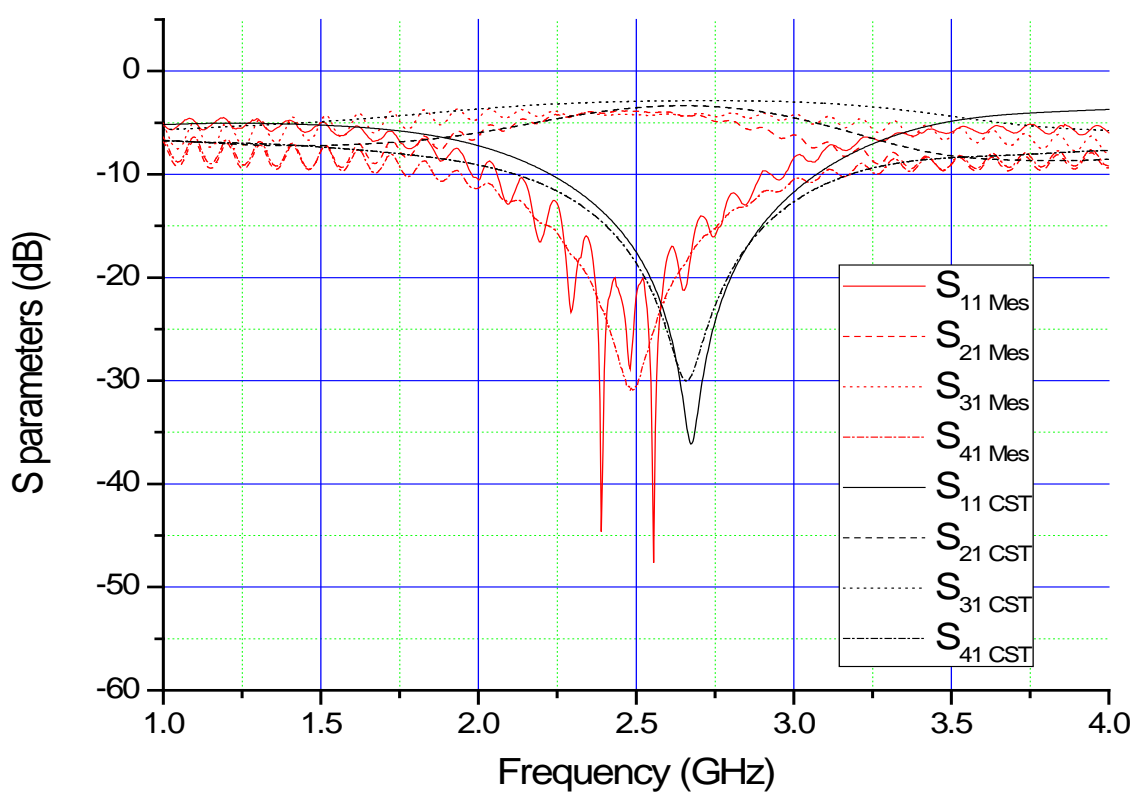

(b)

Figure 14. (a) Proposed 3/6 dB coupler measured and IE3D simulated $S$-parameters at short state; (b) Proposed 3/6 dB coupler measured and CST simulated $S$-parameters at short state.

\section{Conclusion}

A reconfigurable $3 / 6 \mathrm{~dB}$ novel branch line coupler was proposed in this paper. A unique feature of the proposed structure is that the tuning is through simple open and short circuit at the BLC's branches' edges. For fabrication simplicity, two structures were fabricated, one for open state and the other for the short one. A $3 \mathrm{~dB}$ BLC was obtained at short state and the $6 \mathrm{~dB}$ BLC was also obtained at open state. Full-wave analysis using both CST and IE3D simulators was applied to the designated reconfigurable $3 / 6 \mathrm{~dB}$ BLC frequency band. Two BLC prototypes were designed and tested at the "on" and "off" states. BLC characteristics at the frequency band were characterized. The measured $S$-parameters confirm the proposed concept of reconfigurable $3 / 6 \mathrm{~dB}$ BLC. The open/short state can be realized using PIN diodes or MEMs switch with only one coupler 
structure considering the PIN diode model in designing process. The same idea can be extended to have 3/6/9 dB coupler. Also a Varactor diode may be used instead of the PIN diodes to have controllable multi coupling branch line coupler with only one structure by changing the applied DC voltages on these varactors.

\section{References}

[1] Pozar, D.M. (2009) Microwave Engineering. John Wiley \& Sons, Hoboken.

[2] Collin, R.E. (2007) Foundations for Microwave Engineering. John Wiley \& Sons, Hoboken.

[3] Lange, J. (1969) Interdigitated Stripline Quadrature Hybrid (Correspondence). IEEE Transactions on Microwave Theory and Techniques, 17, 1150-1151. https://doi.org/10.1109/TMTT.1969.1127115

[4] Osmani, R.M. (1981) Synthesis of Lange Couplers. IEEE Transactions on Microwave Theory and Techniques, 29, 168-170. https://doi.org/10.1109/TMTT.1981.1130316

[5] Han, L., Wu, K. and Chen, X. (2009) Accurate Synthesis of Four-Line Interdigitated Coupler. IEEE Transactions on Microwave Theory and Techniques, 57, 2444-2455. https://doi.org/10.1109/TMTT.2009.2029630

[6] Cho, J.H., Hwang, H.Y. and Yun, S.W. (2005) A Design of Wideband 3-dB Coupler with N-Section Microstrip Tandem Structure. IEEE Microwave and Wireless Components Letters, 15, 113-115. https://doi.org/10.1109/LMWC.2004.842850

[7] Moon, S.W., Han, M., Oh, J.H., Rhee, J.K. and Kim, S.D. (2006) V-Band CPW 3-dB Tandem Coupler Using Air-Bridge Structure. IEEE Microwave and Wireless Components Letters, 16, 149-151. https://doi.org/10.1109/LMWC.2006.872151

[8] Tang, C.W., Tseng, C.T. and Hsu, K.C. (2013) Design of the Modified Planar Tandem Couplers with a Wide Passband. IEEE Transactions on Microwave Theory and Techniques, 61, 48-54. https://doi.org/10.1109/TMTT.2012.2226745

[9] Nedil, M., Denidni, T.A. and Talbi, L. (2006) Novel Butler Matrix Using CPW Multilayer Technology. IEEE Transactions on Microwave Theory and Techniques, 54, 499-507. https://doi.org/10.1109/TMTT.2005.860490

[10] Wang, J., Wang, B.Z., Guo, Y.X., Ong, L.C. and Xiao, S. (2007) A Compact SlowWave Microstrip Branch-Line Coupler with High Performance. IEEE Microwave and Wireless Components Letters, 17, 501-503. https://doi.org/10.1109/LMWC.2007.899307

[11] Zong, B.F., Wang, G.M., Zhang, C.X. and Wang, Y.W. (2014) Miniaturized BranchLine Coupler with Ultra-Wide High Suppression Stopband. Electronics Letters, 50, 1365-1367. https://doi.org/10.1049/el.2014.1150

[12] Hosseini, F., Hosseini, M.K.A. and Yazdani, M. (2009) Novel Compact Branch-Line Coupler Using Non-Uniform Transmission Line. 2009 Asia Pacific Microwave Conference, Singapore, 7-10 December 2009, 1577-1580.

https://doi.org/10.1109/APMC.2009.5384390

[13] Mou, C.H. and Tseng, C.H. (2011) A Bandwidth-Enhanced 3-dB Lumped-Element Branch-Line Coupler Based on Asymmetrical E-Equivalent Sections. 2011 Asia-Pacific Microwave Conference, Melbourne, 5-8 December 2011, 29-32.

[14] Wang, Y., Ma, K. and Mou, S. (2016) A Compact Branch-Line Coupler Using Substrate Integrated Suspended Line Technology. IEEE Microwave and Wireless Components Letters, 26, 95-97. https://doi.org/10.1109/LMWC.2016.2517158 
[15] Bhowmik, P., Moyra, T. and Deb, P.K. (2015) Size Miniaturization of 3 dB Branch Line Coupler by Using Open Stubs. 2015 2nd International Conference on Signal Processing and Integrated Networks, Noida, 19-20 February 2015, 642-645. https://doi.org/10.1109/spin.2015.7095279

[16] Cao, Y., Wen, J., Hong, H. and Liu, J. (2015) A Compact Branch-Line Coupler with Arbitrary Power Division and Multi Frequencies Suppression. 2015 IEEE 16th International Conference on Communication Technology, Hangzhou, 18-20 October 2015, 376-379.

[17] Wu, G.C., Wang, G.M., Sun, B. and Wang, Y.W. (2013) Design of Miniaturized Branch-Line Coupler Based on Novel Spiral-Interdigital Resonator Cells. Microwave and Optical Technology Letters, 55, 2750-2753.

https://doi.org/10.1002/mop.27937

[18] Tang, C.W., Tseng, C.T. and Hsu, K.C. (2014) Design of Wide Passband Microstrip Branch-Line Couplers with Multiple Sections. IEEE Transactions on Components, Packaging and Manufacturing Technology, 4, 1222-1227. https://doi.org/10.1109/TCPMT.2014.2320499

[19] Cst Studio Suite 2014. Computer Simulation Technology Inc.

[20] Zeland Software Package, Version 12. Zeland Software Inc.

[21] Garg, R., Bahl, I. and Bozzi, M. (2013) Microstrip Lines and Slotlines. Artech House, Boston.

[22] Urbanavicius, V., Mikucionis, S. and Martavicius, R. (2015) Model of the Coupled Transmission Lines with a Non-Uniform Dielectric. Electronics and Electrical Engineering, 77, 23-28.

\section{Submit or recommend next manuscript to SCIRP and we will provide best} service for you:

Accepting pre-submission inquiries through Email, Facebook, LinkedIn, Twitter, etc. A wide selection of journals (inclusive of 9 subjects, more than 200 journals)

Providing 24-hour high-quality service

User-friendly online submission system

Fair and swift peer-review system

Efficient typesetting and proofreading procedure

Display of the result of downloads and visits, as well as the number of cited articles

Maximum dissemination of your research work

Submit your manuscript at: http://papersubmission.scirp.org/

Or contact ojapr@scirp.org 